\title{
IMMOBILIZATION OF LACCASE IN ALGINATE BEADS
}

\author{
BÉla VARGA*1, MÓNIKA MEICZINGER ${ }^{2}$, AND VIOLA SOMOGYI ${ }^{1}$ \\ ${ }^{1}$ Institute of Environmental Engineering, University of Pannonia, Egyetem u. 10, Veszprém, 8200, \\ HUNGARY \\ ${ }^{2}$ Research Institute of Biomolecular and Chemical Engineering, University of Pannonia, Egyetem u. 10, \\ Veszprém, 8200, HUNGARY
}

\begin{abstract}
The elimination or degradation of micropollutants from wastewater is becoming ever more important nowadays. Using oxidoreductase enzymes to treat different micropollutants seems a promising solution. However, the viability of the process is highly dependent on the availability and stability of the applied enzymes. In order to improve the stability and provide faster reaction rates, enzymes can be immobilized in various carriers. Properties such as simple production, easy retention and biodegradable carrier material are advantageous, e.g. entrapping laccase in alginate beads. This paper shows the results of the preparation and characterization of immobilized laccase entrapped in calcium alginate beads. The technique of adding a mixture of sodium alginate and laccase dropwise into calcium chloride has been applied, improved and standardized to produce laccase-containing beads of uniform size and activity. For the purpose of characterization, a widely used substrate, 2,2'-azino-bis(3-ethylbenzothiazoline-6-sulfonic acid) diammonium salt, was used to evaluate the performance of the laccase-containing alginate beads. In addition to the characterization of the laccase-containing alginate beads, the enzyme kinetic constants $\left(K_{\mathrm{M}}=26.43 \mu \mathrm{M}, V_{\max }=0.23 \mu \mathrm{M} / \mathrm{min}\right)$ were determined. The reduction in the activity during storage has been described by a decay constant $\left(0.26 \mathrm{~d}^{-1}\right)$ that provides information concerning the design constraints of the process. Results will be used to test the method in terms of the removal of organic micropollutants in continuous systems.
\end{abstract}

Keywords: laccase, immobilization, alginate, ABTS, micropollutants

\section{Introduction}

Awareness concerning the spread of micropollutants in water bodies has been raised in many countries [1] due to their toxic effects on ecological systems [2]. Additionally, these pollutants can infiltrate into reservoirs of drinking water in several ways resulting in public health concerns [3]. Since conventional treatment systems were designed to easily remove biodegradable compounds [4], the efficiency of micropollutant degradation is insufficient [5]. The partial elimination of these substances is driven by physical adsorption by the sludge [6] and cometabolism during microbial growth [7]. Therefore, the development of advanced technologies to improve the efficiency of removal and mitigate ecological effects is needed [8].

Organic micropollutants could be converted by oxidoreductase enzymes such as tyrosinase, peroxidase and laccase. Laccase has received attention since it does not require additional cofactors. It promotes the production of an organic radical which combines with different transformation products [9]. The toxicity of these compounds is a subject of ongoing research [10], although a reduction in toxicity has been shown in many cases [11].

\footnotetext{
*Correspondence: vargabela@almos.uni-pannon.hu
}

Immobilization can be advantageous compared to the free form of the enzyme [12]. It can enhance the stability of the enzymes under more extreme conditions, namely higher $\mathrm{pH}$ and temperature [13], and makes the separation of the catalyst from the effluent easier. For example, separation by applying an external magnetic force is possible when laccase is immobilized on magnetic particles [14]. By using macro-sized supports, e.g. alginate beads [15] - unlike nanoparticles - the carriers can be retained by an outlet sieve, thus using them in continuous packedbed reactors is possible [16].

Alginates extracted from brown algae [17] are good candidates for water treatment because of their advantageous properties [18], low-cost production and low health risks [19]. Calcium alginate microspheres, successfully used to immobilize polygalacturonase for the purpose of cleaning edible products, have shown improved operational stability as the optimum temperature increases and even modifies the $\mathrm{pH}$ dependence of the enzyme [20]. Calcium alginate beads are formed by reversible crosslinking bonds with bivalent calcium ions between chains of $\alpha$-L-guluronic acid and $\beta$-D-mannuronic acid [19]. Their unique properties allow them to be used as an adsorbent for dye removal [21]. Transformation of the phe- 
nolic compound with laccase entrapped in alginate was successfully tested for bisphenol A [22] and the decolourization of textile dyes [23].

The aim of this study was to investigate the immobilization of laccase in calcium alginate beads and determine its kinetic behaviour by measuring the conversion of 2,2'-azino-bis(3-ethylbenzothiazoline-6-sulfonic acid) diammonium salt (ABTS). Since this substrate is widely used, the results may be easily compared with other laccase immobilization methods.

\section{Materials and methods}

\subsection{Materials}

Laccase from Trametes versicolor (catechol oxidase activity $\geq 0.5 \mathrm{U} / \mathrm{mg}$ ) and ABTS were purchased from Sigma-Aldrich. Food grade sodium alginate was purchased from Dragonspice Naturwaren. Citric acid and sodium phosphate used for making McIlvaine buffer solution [24] were supplied by VWR International. Calcium chloride was purchased from REANAL. Reagents were of analytical reagent grade except for sodium alginate.

\subsection{Measurement of enzyme activity}

Laccase activity was determined by measuring the change in concentration of the ABTS radical formed in the catalysed oxidation. Measurements were performed in a Macherey-Nagel Nanocolor UV/VIS spectrophotometer at $420 \mathrm{~nm}$ in a citrate-phosphate buffer solution at $\mathrm{pH}=5$ and within the range of laboratory temperatures $\left(20 \pm 3{ }^{\circ} \mathrm{C}\right)$. The formation of the product was registered by using the extinction coefficient of the ABTS radical ( $\varepsilon=36,000 \mathrm{M}^{-1} \mathrm{~cm}^{-1}$ [25]) and calculated using an equation

$$
A=\frac{E V_{\text {sample }}}{l \varepsilon V_{\text {total }}}
$$

based on the Beer-Lambert law [26], where $A$ denotes the activity (U/l), $E$ is a measure of the change in absorbance at $420 \mathrm{~nm}$ over 1 minute $\left(\mathrm{min}^{-1}\right), V_{\text {sample }}$ represents the amount of enzyme contained in the sample used $(\mathrm{ml}), l$ is the pathlength of the beam of light $(\mathrm{cm}), \varepsilon$ stands for the extinction coefficient of the ABTS radical $\left(\mathrm{M}^{-1} \mathrm{~cm}^{-1}\right)$, and $V_{\text {total }}$ expresses the total volume used $(\mathrm{ml})$.

In the case of immobilized laccase, beads were placed into the tubes instead of the liquid samples. The specific activity was calculated by measuring the weight and number of beads before the activity in a closed tube was measured. Between measurements, the beads were stored in distilled water in order to minimize the loss of water.

\subsection{Immobilization of laccase inside an algi- nate matrix}

The immobilization protocol was based on entrapment of the enzyme before the formation of insoluble alginate beads according to Daâssi et al. [23]. The sodiumalginate crystals were dissolved in $5 \mathrm{ml}$ of $1 \mathrm{mg} / \mathrm{ml} \mathrm{lac-}$ case stock solution to produce a gel with $2 \mathrm{w} / \mathrm{v} \%$ alginate content. This was added dropwise from a height of $25 \mathrm{~cm}$ into a $2 \mathrm{~m} / \mathrm{m} \%$ solution of calcium chloride where beads formed, then the beads were left for 30 mins to solidify. After this procedure, the beads were extracted from the solution by filtration and washed with distilled water in order to eliminate the unbonded laccase. The beads were stored in distilled water until used for further investigations.

The efficiency of the immobilization was determined by measuring the activities of the laccase stock solution ( $\left.A_{\text {initial }}\right)$, the solution of calcium chloride after immobilization $\left(A_{\mathrm{CaCl}_{2}}\right)$ and the washing liquid ( $\left.A_{\text {washing }}\right)$ used. Immobilization efficiency $(\eta)$ was calculated using the following formula

$$
\eta(\%)=100 \frac{A_{\text {initial }}-A_{\mathrm{CaCl}_{2}}-A_{\text {washing }}}{A_{\text {initial }}} .
$$

\subsection{Characterization of the immobilized lac- case}

The weight was measured frequently in a closed vessel by using an analytical balance (Kern ABJ 220-4NM). The size of the drops was determined by measuring the diameter of the freshly prepared beads after filtration on a square membrane filter. In order to determine the water content, twenty pieces of freshly prepared beads were put into an oven at a temperature of $105^{\circ} \mathrm{C}$ and dried until their weight became constant.

\subsection{Effect of temperature on alginate beads}

In order to gather information regarding the effect of temperature on enzyme activity within the optimal temperature range of wastewater treatment plants [27], the reaction rate of the ABTS transformation was determined inside a thermostatic cabinet $\left(20-35^{\circ} \mathrm{C}\right)$.

\subsection{Storage stability of the beads}

The storage stability of the immobilized laccase was determined by storing the laccase-containing beads in ultrapure water at $20^{\circ} \mathrm{C}$ without mixing. Beads were removed every 24 hours from the vessel in order to determine the change in their activity. The exponential decay constant was calculated by fitting the following equation

$$
A_{t}=A_{\text {initial }} e^{-k_{\mathrm{d}} t}
$$

to the measured activities, where $A_{\text {initial }}$ and $A_{t}$ indicate the specific activities [U/bead] at the initial and given time, respectively, $k d$ denotes the decay constant $\left[\mathrm{d}^{-1}\right]$ and $t$ stands for the time of sampling [h].

\subsection{Reuse of the alginate beads}

The laccase-containing beads were mixed with a 0.05 $\mathrm{mg} / \mathrm{ml} \mathrm{ABTS}$ solution in a phosphate-citrate buffer solution $(\mathrm{pH}=5)$ and the change in the ABTS radical concentration was determined spectrophotometrically. After 
A

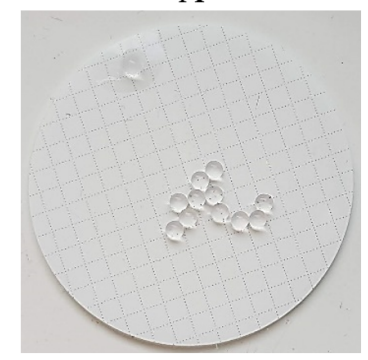

Figure 1: Change of size during drying of the beads (A) beads freshly prepared, (B) beads after drying, grid size: $3 \mathrm{~mm}$

measuring the activity of the beads (after 5 mins), they were filtered and washed with $5 \mathrm{ml}$ of distilled water which was considered to be one cycle. During the filtration, a picture was taken to document the change in the size and shape of the beads. After washing, the beads were put into a fresh volume of buffer solution that contained ABTS and the same cycle repeated six more times.

\subsection{Determination of kinetic parameters with ABTS}

Ten beads were put into a $\mathrm{pH}=5$ citrate-phosphate buffer solution, then different amounts of ABTS stock solution were pipetted in order to obtain different initial substrate concentrations $([\mathrm{S}]=23,46,91,228,456$, and $911 \mu \mathrm{M})$. The change in absorbance was recorded at $420 \mathrm{~nm}$ to calculate the concentration of ABTS radicals (P). The Michaelis-Menten constant (KM) and maximum rate of reaction $\left(V_{\max }\right)$ were determined by fitting the Michaelis-Menten equation.

$$
\frac{d[\mathrm{P}]}{d t}=\frac{V_{\max }[S]}{K_{\mathrm{M}}+[\mathrm{S}]}
$$

with non-linear regression.

\section{Results and Analysis}

\subsection{Characterization of the alginate beads}

Using the technique described, it was possible to produce a uniform bead weight: $0.0152 \mathrm{~g}(\mathrm{SD}=0.0016 \mathrm{~g}$ ) of high immobilization efficiency $(98.2 \%)$. The diameters of the beads were between 2 and $3 \mathrm{~mm}$. The weight and density of the beads constantly changed during their handling due to the rapid rate of evaporation of water. Therefore, the number of beads was used to calculate the specific activity instead of weight, in a similar way to Daâssi et al. [23]. A specific activity of $0.005 \mathrm{U} /$ bead was achieved, which equates to $0.005 \mu \mathrm{M}$ production of ABTS radicals in one minute. The water content of the beads was determined to be $98 \pm 1 \%$. The size of the beads shrank twofold whilst being dried as is shown in Fig. 1.

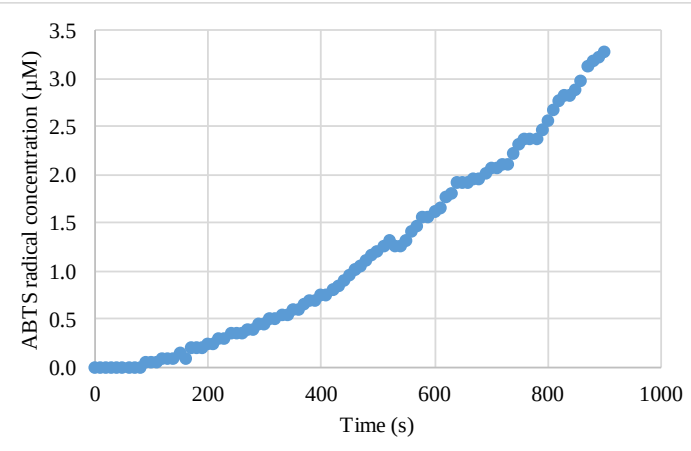

Figure 2: Change of ABTS radical concentration

\subsection{Determination of kinetic parameters}

The change in the concentration of ABTS radicals as a function of time is presented in Fig. 2. A linear curve could be fitted with the results during the initial 2 minutes indicating a first-order reaction. The rate of the reaction can be determined from the gradient of the curves. By plotting the initial rates of reaction against the concentration of the substrate, a lower initial substrate concentration shows a better fit $\left(R^{2}=0.96-0.99\right)$ when compared to the higher range $\left(R^{2}=0.95\right)$.

As a result, common Michaelis-Menten kinetics were shown (Fig. 3). By fitting an equation to the data gathered from three independent experiments with nonlinear least squares regression, the kinetic constants can be determined, namely $K_{\mathrm{M}}=26.43 \mu \mathrm{M}, V_{\max }=0.23 \mu \mathrm{M} / \mathrm{min}$.

\subsection{Effect of temperature on alginate beads}

In the range of $20-35{ }^{\circ} \mathrm{C}$, the rate of reaction, thus the enzyme activity, increased rapidly as can be seen in Fig. 4. As expected, the highest activity was measured at 35 ${ }^{\circ} \mathrm{C}$ since, in the case of the free laccase from Trametes versicolor, the optimal temperature for maximum activity was approximately $40{ }^{\circ} \mathrm{C}$ [26].

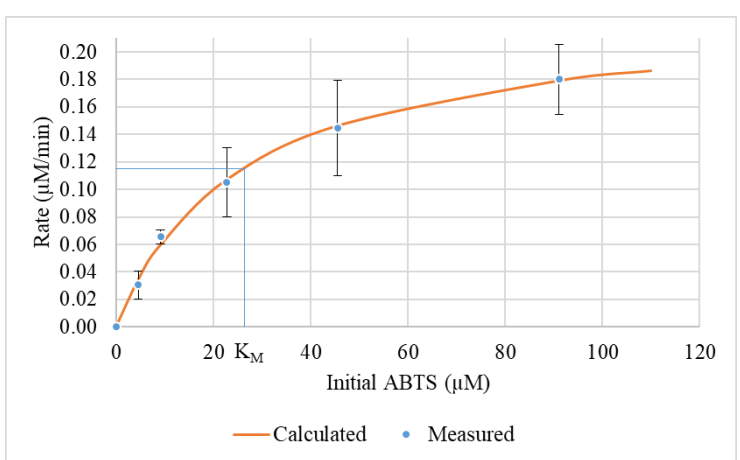

Figure 3: Fitting of Michaelis-Menten curve to the measure. Initial concentrations used for calculation: $5 \mu \mathrm{M}, 9$ $\mu \mathrm{M}, 23 \mu \mathrm{M}, 46 \mu \mathrm{M}, 91 \mu \mathrm{M}$. 


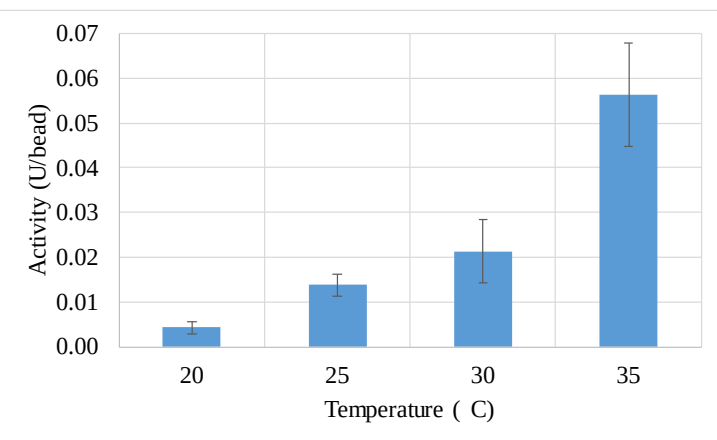

Figure 4: Effect of temperature on the activity of the immobilized enzyme.

\subsection{Storage stability of the beads}

During storage, a slow decreasing trend can be observed in the activity of the beads, namely a reduction of $33 \%$ over 5 days. By fitting equation to the measured values, the decay coefficient can be determined as $0.26 \mathrm{~d}^{-1}$. The change in activity and the decay curve produced by the equation are presented in Fig. 5.

\subsection{Reuse of the beads}

The activity of the beads also decreased when repeatedly used. As an example, the results of an experiment were presented in Fig. 6. While the activity of the beads decreased, their weight increased gradually. The change in the size of the beads and accumulation of the green reaction products can be seen in Fig. 7. This figure also shows the deformation of the beads in between the experiments.

\section{Discussion}

Using the method described in this study, uniform beads can be produced with regard to their size and weight by controlling the size of their droplets and the height from which they are dropped. Since the alginate powder was dissolved directly in the stock solution of laccase and the thick layer solidified instantly when it came

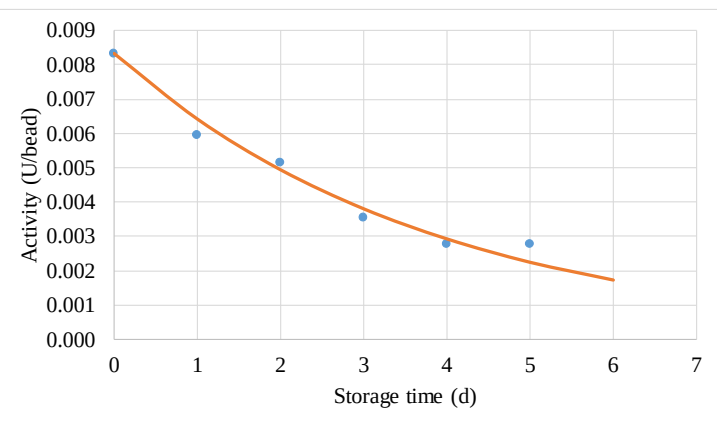

- Measured Calculated

Figure 5: Change of the activity during storage of the immobilized laccase.

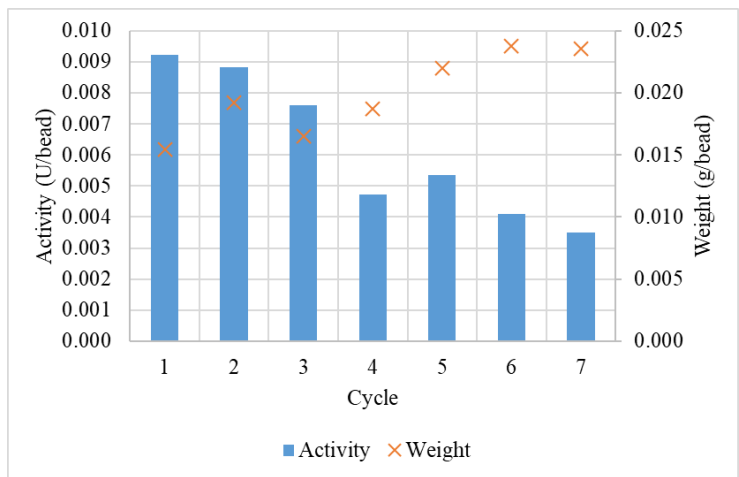

Figure 6: Change of activity and weight of the beads during reuse

into contact with the $\mathrm{CaCl}_{2}$ solution, the entrapment was instant and effective. As a result, a high immobilization efficiency was achieved (98.2\%). Otherwise, the weight of the beads changed quickly whilst being handled after their formation as the beads dried out easily. However, the change in their water content did not influence their activities. Therefore, in order to achieve reliable results for specific activities, the number of beads was calculated rather than their weight.

Evaluation of the reaction kinetics resulted in a Michaelis-Menten curve in the case of immobilized laccase, in a similar manner to its free form [28]. This indicates that the mechanism of the reaction was not influenced by the entrapment. Nonetheless, the activity of the beads is different from that of free laccase due to steric effects and limitations with regard to the diffusion of reactants. In order to achieve higher degrees of activity, the temperature could be increased. This would have advantageous effects on the rate of reaction and diffusion. Additionally, by increasing the number of beads used, the rate of reaction could be fine-tuned to suit the requirements of their application in a similar way to the use of free enzymes. In order to determine the product yield or space-time yield, further investigations are recommended.

Due to the nature of ABTS, from visual inspection of radicals in itself, it was evident that the reaction products accumulate inside the beads (see Fig. 7). This could result in the deactivation of the enzyme by product inhibition. On the other hand, this phenomenon could be used to remove the transformation products after enzymatic conversion by means of adsorption. As Tanaka et al. [29] concluded, the diffusion properties depend on the molecular size of the substrate. Since laccase-catalysed reactions tend to result in coupled products of higher molecular weight [9], its release from the beads could be limited by diffusion. In the case of low-molecular-weight compounds, e.g. ABTS, free diffusion can be assumed in the alginate matrix [30].

As the experiments concerning repeated usage have shown, the beads suffer from major structural changes 


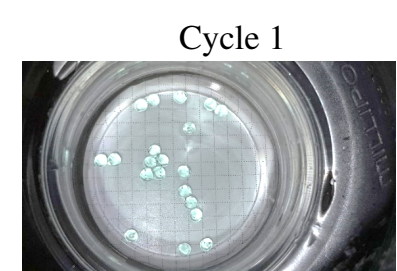

Cycle 3

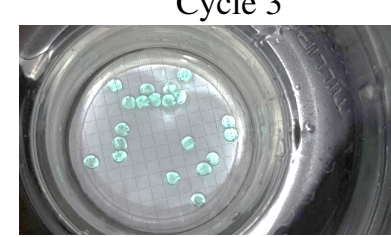

Cycle 5

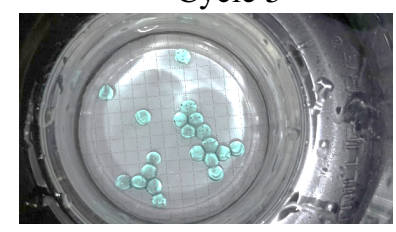

Cycle 7

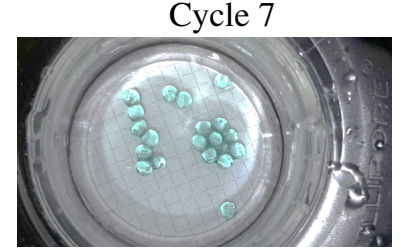

Figure 7: Photos of the laccase containing alginate beads during the repeated use

in buffer solutions that contain high concentrations of monovalent cations. This is due to the fact that crosslinking with calcium ions is reversible. These structural changes may result in the enzyme leaking and the specific activity decreasing following repeated usage. The reduction in enzyme activity during storage could also be a result of leakage. However, experiments performed in distilled water fitted well with the decay equation, therefore, this can be taken into consideration during the design of the process. Moreover, in the case of a complex solution, e.g. treated wastewater or even tap water, the presence of bivalent cations may limit the deformation of the beads.

\section{Conclusions}

Uniformly sized alginate beads were produced in the laboratory using a widely available biodegradable polymer. The mechanism of immobilized laccase was similar to that of its free form with regard to the conversion of ABTS, although the effects of diffusion and adsorption should be taken into consideration. Due to the structure of the alginate beads, the use of monovalent ions that contain buffers for measurements results in major structural changes. The beads produced were reused successfully over 7 cycles, while a rapid reduction in activity and structural changes were observed. However, the beads can be stored in distilled water and the reduction in ac- tivity estimated by an exponential decay equation which facilitates the design of the process. Although further investigations regarding the efficiency of enzymatic transformation are needed, immobilization of laccase in alginate beads is a promising technique for the enzymatic treatment of micropollutants in continuous systems.

\section{Symbols}

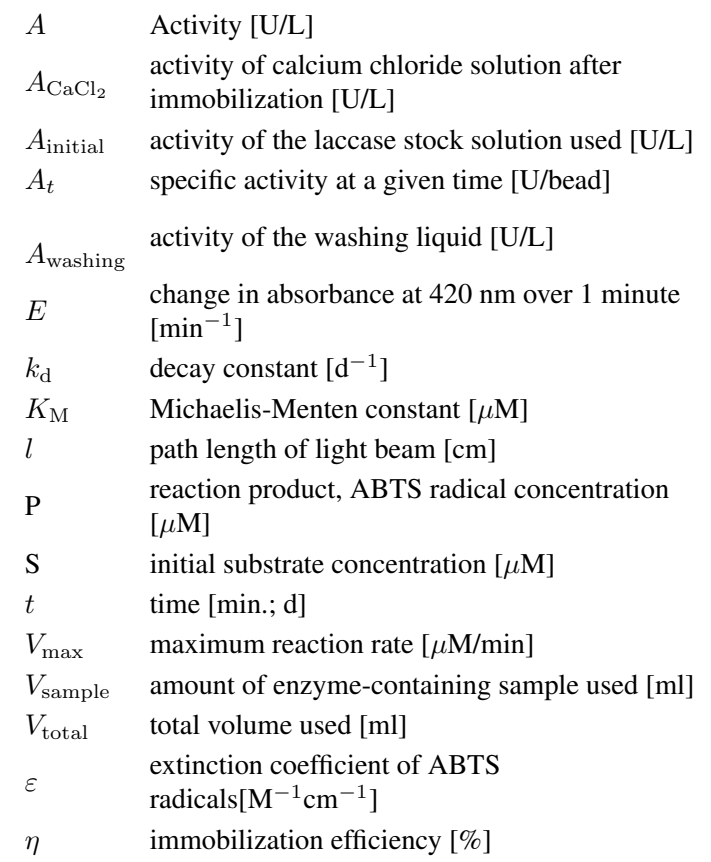

\section{Acknowledgement}

The financial support of Széchenyi 2020 under the projects GINOP-2.3.2-15-2016-00016 and TÉT_15_IN$1-2016-0094$ is greatly appreciated.

\section{REFERENCES}

[1] Ebele, A.J.; Abou-Elwafa Abdallah, M.; Harrad, S.: Pharmaceuticals and personal care products (PPCPs) in the freshwater aquatic environment. Emerg. Contam., 2017 3(1), 1-16 DOI: 10.1016/j.emcon.2016.12.004

[2] Shao, Y.; Chen, Z.; Hollert, H.; Zhou, S.; Deutschmann, B.; Seiler, T.-B.: Toxicity of 10 organic micropollutants and their mixture: Implications for aquatic risk assessment. Sci. Total Environ., 2019 666, 1273-1282 DOI: 10.1016/j.scitotenv.2019.02.047

[3] Ahmad, J.; Naeem, S.; Ahmad, M.; Usman, A.R.A.; Al-Wabel, M.I.: A critical review on organic micropollutants contamination in wastewater and removal through carbon nanotubes. J. Environ. Manage., 2019 246, 214-228 DOI: 10.1016/j.jenvman.2019.05.152

[4] Monteiro, S.C.; Boxall, A.B.A.: Occurrence and Fate of Human Pharmaceuticals in the Environment. In: Reviews of Environmental Contamination 
and Toxicology. (Springer New York: New York, NY, 2010), pp. 53-154 DOI: 10.1007/978-1-4419-1157$5 \_2$

[5] Grandclement, C.; Seyssiecq, I.; Piram, A.; WongWah-Chung, P.; Vanot, G.; Tiliacos, N.; et al.: From the conventional biological wastewater treatment to hybrid processes, the evaluation of organic micropollutant removal: A review. Water Res., 2017 111, 297-317 DOI: 10.1016/j.watres.2017.01.005

[6] Berthod, L.; Roberts, G.; Sharpe, A.; Whitley, D.C.; Greenwood, R.; Mills, G.A.: Effect of sewage sludge type on the partitioning behaviour of pharmaceuticals: A meta-analysis. Environ. Sci. Water Res. Technol. 2016 2, 154-163 DOI: 10.1039/c5ew00171d

[7] Torresi, E.; Tang, K.; Deng, J.; Sund, C.; Smets, B.F.; Christensson, M.; et al.: Removal of micropollutants during biological phosphorus removal: Impact of redox conditions in MBBR. Sci. Total Environ., 2019 663, 496-506 DOI: 10.1016/j.scitotenv.2019.01.283

[8] Bui, X.T.; Vo, T.P.T.; Ngo, H.H.; Guo, W.S.; Nguyen, T.T.: Multicriteria assessment of advanced treatment technologies for micropollutants removal at large-scale applications. Sci. Total Environ., 2016 563-564, 1050-1067 https://doi.org/10.1016/j. scitotenv.2016.04.191

[9] Catherine, H.; Penninckx, M.; Frédéric, D.: Product formation from phenolic compounds removal by laccases: A review. Environ. Technol. Innov., 2016 5, 250-266 DOI: 10.1016/j.eti.2016.04.001

[10] Becker, D.; Varela Della Giustina, S.; RodriguezMozaz, S.; Schoevaart, R.; Barceló, D.; de Cazes, M.; et al.: Removal of antibiotics in wastewater by enzymatic treatment with fungal laccase - Degradation of compounds does not always eliminate toxicity. Bioresour. Technol., 2016 219, 500-509 DOI: 10.1016/j.biortech.2016.08.004

[11] Varga, B.; Somogyi, V.; Meiczinger, M.; Kováts, N.; Domokos, E.: Enzymatic treatment and subsequent toxicity of organic micropollutants using oxidoreductases - A review. J. Clean. Prod., 2019 221, 306322 DOI: 10.1016/j.jclepro.2019.02.135

[12] Brandi, P.; D’Annibale, A.; Galli, C.; Gentili, P.; Pontes, A.S.N.: In search for practical advantages from the immobilisation of an enzyme: the case of laccase. J. Mol. Catal. B Enzym., 2006 41(1-2), 6169 DOI: 10.1016/j.molcatb.2006.04.012

[13] Bilal, M.; Asgher, M.: Dye decolorization and detoxification potential of Ca-alginate beads immobilized manganese peroxidase. BMC Biotechnol., 2015 15, 111 DOI: 10.1186/s12896-015-0227-8

[14] Rouhani, S.; Rostami, A.; Salimi, A.: Preparation and characterization of laccases immobilized on magnetic nanoparticles and their application as a recyclable nanobiocatalyst for the aerobic oxidation of alcohols in the presence of TEMPO. RSC Adv., 2016 6, 26709-26718 DOI: 10.1039/c6ra00103c
[15] Hegedüs, I.; Nagy, E.: Comparison of the Structure and the Stability of Single Enzyme Nanoparticles. Hungarian J. Ind. Chem., 2009 37(2), 123-130.

[16] Niladevi, K.N.; Prema, P.: Immobilization of laccase from Streptomyces psammoticus and its application in phenol removal using packed bed reactor. World J. Microbiol. Biotechnol., 2008 24(7), 12151222 DOI: 10.1007/s11274-007-9598-x

[17] Gao, F.; Liu, X.; Chen, W.; Guo, W.; Chen, L.; Li, D.: Hydroxyl radical pretreatment for lowviscosity sodium alginate production from brown seaweed. Algal Res., 2018 34, 191-197 DOI: 10.1016/j.algal.2018.07.017

[18] Fazekas, B.; Pitás, V.; Thury, P.; Kárpáti, Á.: Examination of the Use of Support Materials of Natural Origin in Wastewater Treatment. Hung. J. Ind. Chem., 2009 37(1), 5-10

[19] Li, Q.; Li, Y.; Ma, X.; Du, Q.; Sui, K.; Wang, D.; et al.: Filtration and adsorption properties of porous calcium alginate membrane for methylene blue removal from water. Chem. Eng. J., 2017 316, 623630 DOI: 10.1016/j.cej.2017.01.098

[20] Deng, Z.; Wang, F.; Zhou, B.; Li, J.; Li, B.; Liang, H.: Immobilization of pectinases into calcium alginate microspheres for fruit juice application. Food Hydrocoll., 2019 89, 691-699 DOI: 10.1016/j.foodhyd.2018.11.031

[21] Merakchi, A.; Bettayeb, S.; Drouiche, N.; Adour, L.; Lounici, H.: Cross-linking and modification of sodium alginate biopolymer for dye removal in aqueous solution. Polym. Bull., 2018 76(7), 35353554 DOI: 10.1007/s00289-018-2557-x

[22] Olajuyigbe, F.M.; Adetuyi, O.Y.; Fatokun, C.O.: Characterization of free and immobilized laccase from Cyberlindnera fabianii and application in degradation of bisphenol A. Int. J. Biol. Macromol., 2019 125, 856-864 DOI: 10.1016/j.ijbiomac.2018.12.106

[23] Daâssi, D.; Rodríguez-Couto, S.; Nasri, M.; Mechichi, T.: Biodegradation of textile dyes by immobilized laccase from Coriolopsis gallica into $\mathrm{Ca}-$ alginate beads. Int. Biodeterior. Biodegrad., 2014 90, 71-78 DOI: 10.1016/j.ibiod.2014.02.006

[24] MacIlvaine, T.C.: A buffer solution for colorimetric comparison. J. Biol. Chem., 1921 49, 183-186

[25] Childs, R.E.; Bardsley, W.G.: The steady-state kinetics of peroxidase with 2,2'-azino-di-(3ethyl-benzthiazoline-6-sulphonic acid) as chromogen. Biochem. J., 1975 145, 93-103 DOI: $10.1042 \% 2 \mathrm{Fbj} 1450093$

[26] Swinehart, D.F.: The Beer-Lambert Law. J. Chem. Educ., 1962 39(1), 333 DOI: 10.1021/ed039p333

[27] van Haandel, A.; van der Lubbe, J.: Handbook of Biological Wastewater Treatment. second ed. (IWA Publishing)

[28] Gupta, N.; Lee, F.S.; Farinas, E.T.: Laboratory evolution of laccase for substrate specificity. $J$. Mol. Catal. B Enzym., 2010 62(3-4), 230-234 DOI: 10.1016/j.molcatb.2009.10.012 
[29] Tanaka, H.; Matsumura, M.; Veliky, I.A.: Diffusion characteristics of substrates in Ca-alginate gel beads. Biotechnol. Bioeng., 1984 26(1), 53-58 DOI: 10.1002/bit.260260111

[30] Puguan, J.M.C.; Yu, X.; Kim, H.: Diffusion char- acteristics of different molecular weight solutes in $\mathrm{Ca}$-alginate gel beads. Colloids Surfaces A Physicochem. Eng. Asp., 2015 469, 158-165 DOI: 10.1016/j.colsurfa.2015.01.027 